Publisher: CSIRO; Journal: CH:Australian Journal of Chemistry

Article Type: research-article; Volume: ; Issue: ; Article ID: CH17359

DOI: $10.1071 / \mathrm{CH} 17359$; TOC Head:

\title{
First Year Introductory Chemistry at the University of Western Australia: Reflections and Perceptions
}

Introductory Chemistry at the University of WA

\section{Tristan D. Clemons, ${ }^{\mathrm{A}}$ Bob Bucat, ${ }^{\mathrm{A}}$ and Dino Spagnoli ${ }^{\mathrm{A}, \mathrm{B}}$}

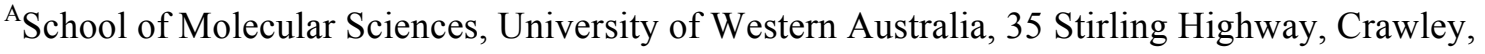
WA 6009, Australia.

${ }^{\mathrm{B}}$ Corresponding author. Email: dino.spagnoli@uwa.edu.au

This study investigated two student cohorts enrolled in an introductory tertiary chemistry unit designed for students with little or no previous education in chemistry. Emeritus Professor Graham Chandler was instrumental in the design and development of this unit almost 30 years ago. Therefore, this study has particular interest in this special issue of the Australian Journal of Chemistry, which celebrates Emeritus Professor Graham Chandler's contribution to Australian chemistry. This paper is divided into two distinct parts that provide two unique perspectives of the unit. The first perspective, Part A, is a historical account of the origins of this unit and is based on an interview with E/Prof. Chandler and Dr Peter Simpson OAM. Both E/Prof. Chandler and Dr Simpson provide an excellent reflection on the need for an introductory chemistry unit in tertiary education, which was not as common then as it is in the present day. The second perspective, Part B, is a research study focussing on the perceptions of students taking this unit in 2013 and 2014. In this study, it was found that the number of students who perceived chemistry to be applicable to real world problems increased during the unit, as did the number of students who enjoyed the unit. However, many students, most of whom did not intend to study chemistry further, did not recognise the application of the content to their future careers. There are many similarities between the aims of E/Prof. Chandler and Dr Simpson for the unit and the perceptions of students taking this unit 30 years later, which is testament to Graham's contribution to chemistry education at the University of Western Australia.

Manuscript received: 29 June 2017.

Manuscript accepted: 12 September 2017.

Published online:.

This study investigated two student cohorts enrolled in an introductory tertiary chemistry unit designed for students with little or no previous education in chemistry. Emeritus Professor Graham Chandler was instrumental in the design and development of this unit almost 30 years ago. Therefore, this study has particular interest in this special issue of the Australian Journal of Chemistry, which celebrates Emeritus Professor Graham Chandler's contribution to Australian chemistry. 


\section{Introduction}

This special issue of the Australian Journal of Chemistry is to celebrate Emeritus Professor Graham Chandler's contribution to chemistry within Australia. We provide an example of E/Prof. Chandler's contribution to chemistry education at the University of Western Australia (UWA) in Part A - Reflections on the Origins of the Introductory Chemistry Unit at the UWA. This reflection discusses the reasons behind the inception and original curriculum design of the introductory chemistry unit, in which students enrol with little or no chemistry knowledge from high school, through an interview with E/Prof. Chandler and Dr Peter Simpson OAM. Dr Simpson was employed as the designer of the curriculum and the first presenter of the unit. This unit is still being offered to students at the UWA. Part B-Students Perceived Motivations for Studying a Tertiary Introductory Chemistry Course is a research study, which gauged student perceptions with regard to several aspects of the unit that E/Prof. Chandler initially designed. In 2013 and 2014 we asked students about their perceptions of the unit at the start and at the end of semester, paying special attention to students' motivations for enrolling and their aspirations beyond the unit. The study was conducted with entire cohort surveys across two consecutive year groups. In addition, several students were selected for more in-depth interview questioning.

\section{Part A - Reflections on the Origins of the Introductory Chemistry Unit at the UWA}

In the early 1990s, E/Prof. Chandler was the deputy head of the Department of Chemistry at the UWA.

E/Prof. Chandler: 'I was deputy head at the time and faculty matters were my responsibility. Pressure (to introduce an introductory chemistry unit) came from other departments in the faculty of science and outside the faculty of where our students went. They were getting lots of students applying who no longer had school chemistry'

At the time, students were allowed to enrol at university in science disciplines, without the necessary prerequisites. Students could study chemistry at the UWA in first year even without having studied chemistry during their final year at high school.

E/Prof. Chandler: 'Nobody stopped anyone from enrolling in chemistry subjects'

Dr Simpson: 'They would do CHEM120 (a first year chemistry unit for students doing a degree in chemistry) but they would battle through it'

Dr Simpson: 'Students (at high school) were encouraged to do the minimum requirement of four subjects for TEE (Tertiary Entrance Exams) to maximise their grades, which is why so many missed chemistry and is part of the reason why introductory chemistry at UWA came about.' 
Publisher: CSIRO; Journal: CH:Australian Journal of Chemistry

Article Type: research-article; Volume: ; Issue: ; Article ID: CH17359

DOI: 10.1071/CH17359; TOC Head:

E/Prof. Chandler: 'Agriculture realised the students were failing in droves due to no chemistry background.'

The discussion at the Faculty of Science then turned to which school within the faculty should develop and teach such an introductory unit. E/Prof. Chandler believed that staff within the Department of Chemistry should teach this unit. However, at the time, his colleagues did not think the same way.

E/Prof. Chandler: 'Now there was pressure at the time from (staff within) the Department of Chemistry to NOT do introductory chemistry as some were saying 'this is not the business of a university chemistry department to be teaching school chemistry. '

E/Prof. Chandler's proposal was finally approved by the Department of Chemistry when news that the Department of Biochemistry was intending to develop the unit if the Department of Chemistry refused.

The next task E/Prof. Chandler had was to develop the curriculum and decide who was qualified to teach the unit.

E/Prof. Chandler: 'Physics had an introductory course and it was a disaster. They had university lecturers lecturing the same sort of way that they would lecture to university physics students and students hated it. Mel (Prof. Sargent) was the Head of the Chemistry Department at the time, he had a stroke of genius and I remember him telling me 'what we need is a school teacher to do this, get that guy Simpson. ',

'That guy Simpson' to whom he was referring had a decorated career in teaching high school chemistry in Western Australia, tertiary chemistry at the University of Sydney, as well as preparing high school students in the Australian Chemistry Olympiad. Dr Simpson liked the idea of an introductory chemistry unit but came on board with a few demands.

Dr Simpson: 'I only remember two of the three demands but my version is, I would be given a proportion of a salary as previously I had just been paid by the hour, and each year my hours for preparation or setting the exams got reduced until the amount of money got less so I would not come back unless I was on a proportion of a salary. My second demand was that I have complete control over setting and establishing the syllabus and the examination method and the marking and pass rate of it.'

E/Prof. Chandler: 'There was no interference on how the course or how the curriculum was designed, that was solely left up to Peter. I just remember I was consulted at the start as to what I thought should go into an introductory unit but that was about it.' 
Publisher: CSIRO; Journal: CH:Australian Journal of Chemistry

Article Type: research-article; Volume: ; Issue: ; Article ID: CH17359

DOI: 10.1071/CH17359; TOC Head:

Evidence on the early establishment of the unit was that it was a tough course. Dr Simpson designed the syllabus so that he could fit the final two high school years of chemistry and half of first year chemistry in a single semester. However, the unit was very successful.

Dr Simpson: 'Students used to say to me, 'How come you tell us we are doing first year chemistry and it's so easy and the stuff we learn at school is so hard?' Now the school syllabus is all about the iron ore process development and electrolysis and all sorts of industrial processes, which are purely descriptive that in my view are there so that students of low ability can learn them off by heart and get through year 11 and 12 examinations. So if you strip all that out and assume that your students are sufficiently intelligent and involved that if they are interested in those processes they could go and read about it or look it up as they now understand the chemistry it is based upon. The focus in the introductory chemistry unit was on theory and understanding and very little on the descriptive stuff.'

E/Prof. Chandler: 'Yes, the unit was a success....the anecdotal evidence (at the time) from the faculty was that chemistry saved its bacon because chemistry had a nasty smell about it in those days and the students were raving about this introductory unit.'

An important factor in the curriculum design, which made it so appealing for students, was that this unit was never intended to be a route for students into a chemistry degree.

E/Prof. Chandler: 'It was there for students doing other things to get a chemistry background, we never thought the unit would be a route for students to do further chemistry'

Still relevant today are the same primary aims and challenges that were apparent nearly 30 years ago. In order to provide a snapshot of student's perceptions of this unit we surveyed students in 2013 and 2014.

\section{Part B - Students Perceived Motivations for Studying a Tertiary Introductory Chemistry Course}

In Australia there has been a decline in student interest and enrolment in chemistry courses in secondary schools. ${ }^{[1-3]}$ A study commissioned by the Australian Academy of Science in 2011 found that 'Twenty years ago, $94 \%$ of year 11 and 12 students were enrolled in science subjects, but last year the figure dropped to $51 \%$.' Although the decline has now slowed, the downward trend continues. ${ }^{[3]}$ The downward trend is also evident in other industrialised countries. ${ }^{[4,5]}$ In contrast to this national trend, the number of students enrolled in science in year 12 over the period 2002-2007 in Western Australia had remained steady. ${ }^{[6]}$ However, during the same period the minimum tertiary entrance rank for admission to science courses at the Western Australian universities had been reduced. ${ }^{[6]}$ This indicates a decrease in the popularity of science 
Publisher: CSIRO; Journal: CH:Australian Journal of Chemistry

Article Type: research-article; Volume: ; Issue: ; Article ID: CH17359

DOI: 10.1071/CH17359; TOC Head:

courses at a tertiary level, perhaps accompanied by a decrease in the quality of students undertaking these courses. Furthermore, the decline in students' enrolling in secondary school chemistry suggests that more students are coming to University with little to no chemistry background and hence the need for tertiary introductory chemistry courses. According to a study commissioned by the Chief Scientist of Australia, the natural and physical sciences experienced the fourth lowest growth rate in Australian university enrolments among 12 fields. ${ }^{[7]}$ This is a worrying statistic in a world becoming more reliant on science and technology in daily life. Hence it is imperative to investigate students' perceptions of chemistry during this critical transitional period from secondary to tertiary level science in Australia in order to further our understanding of the reasons behind these evident declines in student numbers.

A recent study by Lyons and Quinn indicating a decline in student enrolments in post compulsory secondary science units in Australia identified three factors that contributed to this decline:

(1) The difficulty that students have in picturing themselves as scientists.

(2) The decrease in the utility value of key science subjects relative to their difficulty, in comparison with other disciplines.

(3) The failure of school science to engage a wider range of students.

Similar findings pertaining to student declining interest and attitudes towards science have been made in other countries over recent decades. ${ }^{[8-11]}$ Furthermore, decades of research have shown that in their first year at university, students consider withdrawing for a range of reasons, including poor course or teacher quality, lack of clarity about what is required for success, or most commonly a mismatch in expectations. ${ }^{[12]}$ Research has shown that a negative student attitude towards chemistry is the dominant factor that affects student willingness to continue to study further chemistry. ${ }^{[13]}$ A study by Zusho et al. demonstrated that when tertiary chemistry students' indicated their confidence to do well in chemistry had decreased, so to did their motivation for the subject and the less likely they were to see the utility or relevance of chemistry to themselves. ${ }^{[14]}$ Further to this, Berg demonstrated that student motivations were highly affected by teacher quality, teacher attitudes, and the learning environment more so than the level of content, favourable schedule, or laboratory activities. ${ }^{\left[{ }^{[15]}\right.}$ Hence it is anticipated that maintaining positive student attitudes, especially in an introductory tertiary chemistry course is paramount for student engagement and success thus providing the context for this study.

This study aimed to gauge student perceptions with regard to several aspects of the introductory chemistry unit across its duration, paying special attention to students' motivations for enrolling and their aspirations beyond the unit. The study was conducted with entire cohort surveys across two consecutive year groups. In addition, selected students were chosen for more 
Publisher: CSIRO; Journal: CH:Australian Journal of Chemistry

Article Type: research-article; Volume: ; Issue: ; Article ID: CH17359

DOI: 10.1071/CH17359; TOC Head:

in-depth one on one interview. We feel these findings will increase the body of knowledge surrounding students transitioning from secondary to tertiary education while also providing insights from these students on why Australia is experiencing both a decline in secondary and tertiary science subjects.

\section{Context of the Study and Experimental}

Only students that have not passed final year high school chemistry can enrol in this unit at the UWA. Depending on program options, the unit may be the only formal chemistry education that some students experience in their Bachelor of Science degrees. The unit is a prerequisite for nine of the non-chemistry majors offered at the UWA. The unit is taught in the first teaching semester of the academic year. The assessment of the unit consists of formative and summative online quizzes conducted throughout semester ( $25 \%$ of final mark), six compulsory laboratory sessions (each $\sim 3 \mathrm{~h}, 25 \%$ ), and a final end-of-semester exam (50\%). This study compared results from two consecutive cohorts of students over two successive years. The 2013 cohort (cohort 1) had 406 initially enrolled in the unit, with 359 students completing the unit requirements, while 2014 (cohort 2) initially had 379 students of whom 340 completed the requirements. Students were invited to participate in this research study by the lead author, whom had no involvement in the teaching and learning of the unit over the 2-year study. Student involvement was voluntary and had no bearing on their grades or outcomes from the unit in accordance with the UWA Human Ethics Approval governing this work (project number RA/4/5939). Completion rates of surveys were high (2013 pre: $n=147,2013$ post: $n=303$, 2014 pre: $n=166$ and 2014 post: $n=170)$. Several voluntary one-on-one short interviews ( $n=$ 20 ) were conducted as a part of the study to provide a richer description of ideas and issues that were facing the students over and above the surveys.

The majority of students enrolled in the unit attended metropolitan secondary schools (cohort 1: $76 \%$, cohort 2: $68 \%$ ), rather than rural schools, and most had attended private schools (cohort 1: 60\%, cohort 2: $58 \%$ ) rather than government schools. Approximately $60 \%$ of the students in both cohorts successfully completed their final year of secondary education without undertaking formal chemistry education in the previous year. The remaining $40 \%$ of students had completed secondary school in a different country, in earlier years, or had transferred their course of study from another tertiary institute. The number of students that failed chemistry in their final years was less than $5 \%$ in both cohorts. A small proportion of international students that enrolled in the unit in both cohorts had completed formal secondary chemistry education in their country of origin, for which the university did not allow credit.

The research methodology comprised written surveys (provided in the Supplementary Material), which were conducted at the beginning of the unit (pre-survey) during the first 
Publisher: CSIRO; Journal: CH:Australian Journal of Chemistry

Article Type: research-article; Volume: ; Issue: ; Article ID: CH17359

DOI: 10.1071/CH17359; TOC Head:

compulsory laboratory class, and again at the end of the unit (post-survey) during the final laboratory session. The laboratory classes were chosen in preference to lectures as these are compulsory components of the unit and this helped with student compliance and high response rates. Many studies have concluded that pen-and-paper style surveys elicit a higher response rate than online surveys. ${ }^{[16-19]}$ Sax et al. found that college students were more likely to complete a paper survey than one online, and described online surveys as a 'methodological alternative to a paper questionnaire, but not necessarily a more fruitful one. ${ }^{,[20]}$ The structure of the survey was developed for this study, where students responded to statements about their own perceptions surrounding different aspects of the unit according to the 5-point Likert scale format as used by others previously. ${ }^{[21]}$ Students were also given a list of statements and were asked to indicate those that best represented their own attitudes towards aspects of the unit as well as open comment boxes for elaboration. Previous instruments used for assessing student perceptions such as the Science Laboratory Environment Inventory (SLEI) or attitudes such as the Test of Science Related Attitudes (TOSRA) developed by Fraser et al. were investigated however due to time constraints with students, a shortened, unit specific instrument was considered advantageous.

The pre-surveys were administered as close to the beginning of the unit as practical to avoid students' perceptions towards chemistry being biased by their participation in the unit. Presurvey responses represented a reflection of their chemistry experiences in secondary school and/or their anticipated perceptions of the chemistry to be addressed in the introductory unit. Post-surveys for both cohorts were conducted at the completion of the final laboratory class, and not after the completion of all teaching and assessment. After the post-survey, students still had a week of lectures and the final exam. At the time of completing the post-survey, no student could be assured of their final grade so it is unlikely that student responses were biased by potential unit outcomes. All surveys conducted were short (maximum time 10 min to complete) and the average voluntary student completion rates as a percentage of those who successfully completed the course requirements were high (cohort 1: 63\%, cohort 2: $49 \%$ ). The survey instruments were designed to contain similar questions in the pre- and post-surveys in order to gauge any change in the students' perceptions of these aspects across the duration of the unit.

Incomplete surveys were not included in the analysis. Open comment boxes were provided to allow the students to elaborate upon their responses. During the pre-survey, students were able to indicate if they would be willing to be involved in future interviews. In cohort 1, students were invited to attend small-group interviews in week 7 of the unit, and again one-on-one interviews were conducted in week 12 near the end of the unit. Unfortunately due to practical reasons it was not possible to get overlap between the students interviewed in week 7 and those interviewed in week 12. The protocols for the interviews are provided in the Supplementary 
Publisher: CSIRO; Journal: CH:Australian Journal of Chemistry

Article Type: research-article; Volume: ; Issue: ; Article ID: CH17359

DOI: 10.1071/CH17359; TOC Head:

Material. All students involved in interviews did so voluntarily and all interviews were recorded and transcribed for analysis. Interviews allowed for direct qualitative triangulation of the trends and changes evident in the pre- and post-survey responses. The interviews were integral in providing qualitative support to the large student surveys.

Finally, a short email survey was presented to all students from cohort 1 remaining at UWA, 2 years following their completion of the introductory chemistry unit. This allowed for an interesting longitudinal assessment of which courses students had specialised in, if these majors were chemistry-based or not, and if students' perceived value of the introductory chemistry unit had changed with hindsight.

\section{Results and Discussions}

\section{Perceptions of Students in Introductory Chemistry}

The interview with E/Prof. Chandler and Dr Simpson raised several key aspects about the unit, which we wanted to evaluate with the students in this study. The aspects include assessing the quality of teaching and facilities provided throughout the unit, student enjoyment of chemistry, applicability of chemistry to real world problems, applicability to future study and career aspirations, student interest in chemistry, perceptions of the unit, and how students felt about the challenge of tackling difficult chemistry concepts. Summary data is presented from both cohorts comparing pre-survey to post-survey responses along with relevant statements from both the focus interviews and student responses in the free response sections of the surveys.

\section{Quality of Teaching and Facilities Provided}

The majority of students in both cohorts indicated that the quality of the teaching and facilities provided were high. Both cohorts in the post-survey were asked to indicate their level of agreement with the following statement: 'I feel the teaching in the unit has been very good.' Students in both cohorts responded with a high level of agreement (above $70 \%$ ). This was further supported by voluntary comments from students stating, for example: 'teaching and enthusiasm are really good,' 'good unit, good lecturers, teaching clarity is great,' and 'I am really enjoying the lectures.' This was further supported in the focus group interviews, in which one student remarked, 'I wasn't really liking chemistry before, but then comes along 'the lecturer' and the lecture slides are really good and really helpful.' The majority of comments made with regard to the quality of teaching were positive. To the survey statement 'The UWA facilities used for the unit are good,' again the majority of students (over $85 \%$ in each cohort) indicated that they agreed or strongly agreed with this statement. This high level of satisfaction with both teacher and facility quality suggest that these two factors should not be significant 
Publisher: CSIRO; Journal: CH:Australian Journal of Chemistry

Article Type: research-article; Volume: ; Issue: ; Article ID: CH17359

DOI: 10.1071/CH17359; TOC Head:

contributing factors to any negative perceptions, which students expressed with respect to other aspects of the unit.

\section{Student Enjoyment of Chemistry}

High levels of student engagement with, or enjoyment of, a subject has been positively correlated with higher levels of student achievement and lower levels of student dropout rates. ${ }^{[24]}$ Students' responses to the pre-survey statement 'I enjoyed chemistry at school' (with reference to their lower school chemistry experiences) were compared with those to the postsurvey statement 'I have enjoyed the introductory chemistry unit'. The findings are displayed in Table 1. It is evident that for both cohorts there was a large increase in the number of students who indicated that they enjoyed the unit in the post-survey compared with at the start of the unit (when reflecting on secondary school). From comparison of pre- and post-survey responses, on average across both cohorts, there was a $20 \%$ increase in the number of students who indicated an increase in enjoyment across the course of the unit. An increase in student enjoyment across the unit is consistent with the anecdotal evidence provided by E/Prof. Chandler and Dr Simpson when the unit was first taught.

The observed positive changes in enjoyment were supported in the student interviews. One student who undertook the unit as a compulsory prerequisite said: 'I hated chemistry before starting the unit. I hated chemistry so much I was thinking 'How am I going to get through this?', However, when asked if they felt their perception had changed, the response was 'yeah it has changed a lot, I am liking it.' Another, who chose the unit as an elective, gave a similar response: 'I thought chemistry was really hard, but now I am understanding, it's not so bad .... I really enjoy the hands-on lab stuff.'

Despite the increase in numbers that indicated enjoyment of chemistry, some students at the end of the unit were not enjoying it. One student, who was studying the unit as a prerequisite, responded, 'I don't like chemistry.' When asked if they felt this was a change of their initial perceptions of chemistry at the start of the unit, they replied 'No, not really.' Another found the pace of the unit too fast and as a result they 'struggled big time' and 'did not enjoy the unit at all.'

Despite these negative comments in the minority, the key finding is the large increase, in both cohorts, in the number of students enjoying the introductory chemistry unit compared with their enjoyment of school chemistry (pre- versus post-survey responses, 23 and $17 \%$ increase for cohort 1 and cohort 2 in agreement levels (Table 1)). Some possible reasons for this include: (1) greater maturity of the students; (2) the pressure to maximize marks in the final year of schooling and in turn avoiding chemistry; (3) some familiarity with school topics that they are revisiting; and (4) access to better resources in the university setting, including online materials, 
Publisher: CSIRO; Journal: CH:Australian Journal of Chemistry

Article Type: research-article; Volume: ; Issue: ; Article ID: CH17359

DOI: $10.1071 / \mathrm{CH} 17359$; TOC Head:

textbooks, and lecturers. Enjoyment and engaging with chemistry was a real focus during the implementation of the unit by Dr Simpson and still is amongst the lecturers of the unit today.

\section{Applicability of Chemistry to Real World Problems}

Research has shown that student engagement and motivation can be enhanced when students link and apply concepts they are learning in the classroom to real world problems and contexts. ${ }^{[25]}$ Similarly, in investigating high school students, Lyons and Quinn found that one of the major reasons that students did not choose secondary science at school beyond compulsory enrolment was their inability to see the utility of science in the context of their own lives. ${ }^{[26]} \mathrm{A}$ study looking at New Zealand middle school students found that student engagement in science is declining and that by year eight there was only a small percentage of students who could actively envisage themselves in a possible adult role in a science, technology, engineering, or mathematics (STEM) career. ${ }^{[27]}$ These findings stimulated us to gauge how the first-year students perceived the applicability of chemistry in their lives.

In the pre-survey, students were asked to indicate their level of agreement with the statement 'I have enjoyed how applicable chemistry is to 'real life' problems', and in the post-survey 'This unit has demonstrated to me how applicable chemistry is to 'real life' problems.' The results are summarised in Table 2 .

Upon completion of the unit, the number of students in both cohorts that perceived chemistry to have greater applicability to real world problems had increased. Discussions in focus groups at the end of the unit provided an insight into possible links between the increase in the number of students that enjoyed chemistry and the increase in the number of students that perceived the applicability of chemistry in their own real world situations. When asked if they had enjoyed the unit and why, some students responded with statements such as 'I have liked it (the unit) a lot as it helps me to understand more about what's happening in chemistry and to apply it to real life is really interesting' and 'I am enjoying it because what you are learning is directly applicable to everyday life.' Students cited examples of application to everyday life as understanding ingredient lists on food packaging to applications in the mining industry.

We can speculate that plausible reasons for increased awareness of the applicability of chemistry to real world problems are: (1) the students are more mature; (2) they are enrolled in other non-chemistry units where they are being exposed to the dependence of other disciplines on chemistry concepts; (3) sound teaching strategy of chemistry lecturers using applications of the content to teach in context. Context-based teaching strategies have been used extensively in secondary chemistry education as a means of motivating students to engage in the subject matter. ${ }^{[28-30]}$ Explorations into the reasons are beyond the scope of this study and are interesting areas to investigate in future studies. However, we believe that the applied focus of the lecturing 
Publisher: CSIRO; Journal: CH:Australian Journal of Chemistry

Article Type: research-article; Volume: ; Issue: ; Article ID: CH17359

DOI: $10.1071 / \mathrm{CH} 17359$; TOC Head:

in this unit on relating core chemistry theory to examples in medicine, industry and everyday instances has supported this correlated increase in enjoyment and understanding of the utility of chemistry.

\section{Application of Chemistry for Further Study and Career Paths}

At both the beginning and end of the unit, students were asked to indicate how applicable they perceived the content of the unit would be in benefitting their future study and/or career. Although the number of students who perceived a greater application of chemistry to real-life problems had increased across the course of the unit (Table 2), a similar trend was not observed in relation to the applicability of chemistry to further study/career paths (Table 3). At the end of the unit, fewer students in both cohorts believed that the applicability of what they had learnt would benefit their future study or career than had initially done so at the beginning of the unit (Table 3).

One student interviewed, who was not enjoying the unit, summarised her extrinsic motivation for doing the unit to get into medicine in the following way: 'The fact that I want to actually pursue medicine, there is no other way around it, so if that's what I have to do then I need to just suck it up and do it.' Another, who cited being 'too stressed' to continue with chemistry in secondary school, said that when they first came to university they started an Arts degree, as they were 'unsure of what they wanted to do.' They are now finding that they are enjoying the chemistry in the unit as they 'have decided they wanted to get into medicine' and they could see the importance of the unit for achieving this goal. So, although many of the students were not able to perceive the relevance of the unit to further studies, it would seem that those planning on studying medicine at least understand the importance of the unit as being a major component of that pathway into a medical degree.

Apart from medical studies, the introductory chemistry unit is a prerequisite for several different majors in the Bachelor of Science degree, which is a foundation for other disciplines such as engineering science, physiology, genetics, and pharmacology. From this study we don't have evidence as to whether students saw the applicability of chemistry at high school to a future career path, although previous studies have shown that the majority of students at this time are still indecisive regarding desired career choices.

On the other hand, for many of the majors that are available to the students, chemistry is not a prerequisite, but it is a recommended subject. At the time of writing this manuscript, students from cohort 1 of the study were in their third year of tertiary education and had committed to a particular major. This allowed for the opportunity to analyse which pathway they had chosen to complete their tertiary studies, something that was not possible during the initial surveys and interviews. 
Publisher: CSIRO; Journal: CH:Australian Journal of Chemistry

Article Type: research-article; Volume: ; Issue: ; Article ID: CH17359

DOI: 10.1071/CH17359; TOC Head:

To investigate student major choices further, a separate survey was conducted and analysed student enrolment records from cohort $1(n=257)$, in their third year of education at the UWA. By this time students had begun studies in their chosen major disciplines, as displayed in Fig. 1. Almost $50 \%$ of those investigated in cohort 1 were studying in courses for which the introductory chemistry unit (or an equivalent unit, green bars) was a prerequisite, $20 \%$ were in courses for which the introductory chemistry unit was recommended (yellow bars) and almost $30 \%$ were found to be studying majors requiring no chemistry units as background at all (red bars, Fig. 1). This was of particular interest as in $201370 \%$ of this cohort was undertaking the introductory chemistry unit as a compulsory subject. With $30 \%$ of the cohort deciding upon majors with no formal chemistry requirement at all, it was of interest to ask the students how relevant they now perceived the introductory chemistry unit, nearing the completion of their majors. To probe this further, the follow up survey also asked students to indicate how applicable the following statements were to them: (1) I feel that knowledge of chemistry in general will benefit my chosen career path, and (2) I feel now that what I learnt in the introductory chemistry unit will benefit my chosen career path, with the student responses $(n=$ 20) displayed in Fig. 2.

With reference to statement (1), $50 \%$ of students who responded recognised chemistry to be very applicable to their chosen career, but only $20 \%$ of those students felt that the chemistry learned in the introductory unit was very applicable to their chosen career (Fig. 2). The majority of students during the introductory chemistry unit, and 2 years following did not see the relevance of the unit content for their chosen career. This is found despite students at the time of studying the unit enjoying its content and a large majority able to see the relevance of chemistry in solving real world problems. Furthermore, the majority of cohort 1 in 2013 did not associate what they learnt in the unit to be applicable for their chosen career path, despite $70 \%$ of cohort 1 choosing majors where it was a prerequisite or highly desirable unit to have completed for their course of study. This raises questions with regards to the content being taught in this unit and its suitability to our students, their career needs, and the needs of the units that have the introductory chemistry unit as a prerequisite. Furthermore it supports E/Prof. Chandler's initial outlook on the unit in that it was 'never anticipated to draw more students into chemistry degrees but was to fill an unmet need in providing a foundation of chemistry for other majors at the UWA.'

\section{Would You Choose Chemistry?}

In the post unit surveys, students of both cohorts were asked 'As of today, if you had no restrictions on further unit choices, would you choose to enrol in another chemistry unit?' with the option to answer either yes, no, or maybe/unsure. The responses from both cohort 1 and 2 are presented in Fig. 3. Despite high levels of student enjoyment (Table 1) most students 
Publisher: CSIRO; Journal: CH:Australian Journal of Chemistry

Article Type: research-article; Volume: ; Issue: ; Article ID: CH17359

DOI: $10.1071 / \mathrm{CH} 17359$; TOC Head:

indicated that they would not enrol in another chemistry unit. This further highlights that the basis for students' decisions about future enrolment and study are much more complex than simply whether they enjoyed the unit. Student focus group interviews support this notion, with students who are studying the unit as a compulsory component of their major citing reasons for studying the unit such as: 'it's a requirement of my engineering degree, this is the only reason I am here,' and 'I am just here to attend class and get through this (the unit).' Based on the qualitative data of the surveys, and also supported by student interviews, the majority of our students see the introductory chemistry unit as a required stepping stone in their progression towards their chosen major. Of those students who selected the unit as an elective, some chose the unit because they 'like chemistry', and others who did not study chemistry in high school, 'only chose the unit for preparation to sit the GAMSAT' (graduate medical school admissions test). This finding suggests students are studying the unit to satisfy course/career requirements, although these same students also indicated they did not see the importance of the chemistry in the unit to their chosen career path.

\section{The Challenge of Difficult Chemistry Concepts}

In Australia, the comparative difficulty of chemistry in relation to other secondary school subjects on offer is seen as a major deterrent to student enrolment. ${ }^{[26]}$ Students were asked to indicate their level of agreement, both 'pre' (with reference to secondary school) and 'post' (with reference to the unit) the unit, to the statement 'I've enjoyed the challenge of learning difficult chemistry concepts.' The results are summarised in Table 4 . We see in both cohorts an increase in the number of students that have enjoyed the challenge of learning difficult chemistry concepts when surveyed at the completion of the unit. A student who had elected to study the unit and was enjoying it stated, 'I enjoy it definitely. It can be difficult but that's also good, you don't want it to be easy.' It would seem that some students relish the challenge of mastering chemistry concepts, although it is also important to recognise, especially in light of earlier presented results, that students may feel a greater sense of accomplishment nearing the end of the unit.

\section{Student Perceptions of the Unit}

Students were asked to indicate their agreement with the suitability of the following keywords with reference to the unit as being; challenging, easy, time consuming, boring, exciting, and/or enjoyable. In the pre-survey students were asked which of the keywords best described their anticipated feelings, and in the post-survey students were asked which of the keywords they had experienced during the unit. The summary of student perceptions of the unit from both cohorts is displayed in Fig. 4. The residual plot in Fig. 4 depicts similar trends seen for both cohorts. When comparing 'pre' results to 'post' we see the following major changes: 
Publisher: CSIRO; Journal: CH:Australian Journal of Chemistry

Article Type: research-article; Volume: ; Issue: ; Article ID: CH17359

DOI: 10.1071/CH17359; TOC Head:

(1) Students overestimated the challenge of the unit (average reduction of $21 \%$ 'pre' versus 'post').

(2) Students underestimated the amount of time the unit would take up (11\% average increase 'pre' versus 'post').

(3) Students underestimated the enjoyment of the unit (average increase $8.5 \%$ 'pre' versus 'post').

On the other hand, an average of just $7 \%$ of students found the unit more boring than they had anticipated. This is almost accounted for by a $6 \%$ reduction in the average number of students that expected to find the unit exciting but did not. A very small percentage of students anticipated the unit would be too easy, and this did not change across either cohort, suggesting that the content of the unit is at an adequate level of difficulty and challenge for the majority of students.

\section{Limitations of this Study}

Despite being informative about students' perceptions of chemistry within the unit, this study does not investigate the reasons why the students did not take chemistry in the final years of high school. This would have made for an interesting comparison, delving deeper into the secondary-tertiary education transition, especially with Dr Simpson's unique perspective on this transition after teaching for several years at the secondary level. Furthermore, this study is a snapshot of only two cohorts and their perceived motivations for studying an introductory chemistry unit and it does not try to provide strategies to engage students with the subject of chemistry. Enhancing the engagement of students in this unit and in the subject of chemistry will be the subject of future studies based on the key findings from this exploratory work into the unit. This study provides insight into the perceived attitudes of students, of whom the majority while at secondary school had no intention of continuing to study further in this subject, as well as a direct perspective from those tasked with the unit's curriculum design and implementation.

\section{Conclusions}

E/Prof. Chandler was instrumental in the origins of a very successful introductory chemistry unit at the UWA. This is but a small example of his contribution to chemistry education at the UWA. The reflections of E/Prof. Chandler and Dr Simpson provided insight into the reasons and motivations for creating the unit. We also learnt that the curriculum engaged and challenged students, which ultimately provided the groundwork for its success over the last 30 years and is something the current practitioners of the unit also strive to attain. The students in 2013 and 2014 found the unit to be challenging, but they enjoyed it nonetheless. Despite this increase in the number of students enjoying the unit, there was a decrease in the number of students who 
Publisher: CSIRO; Journal: CH:Australian Journal of Chemistry

Article Type: research-article; Volume: ; Issue: ; Article ID: CH17359

DOI: 10.1071/CH17359; TOC Head:

could see the applicability of chemistry to future study or career. It is postulated that student enjoyment of the subject is linked to recognition of the applicability of chemistry to real life situations and that, in turn, this could encourage student retention. However, in this study, the enjoyment and increased engagement of chemistry did not impact on student retention in the discipline: less than a third of students indicated that they would elect to take another chemistry unit if they had no course restrictions. However, this was never the intention of the unit that was developed. E/Prof. Chandler had the wisdom to recognise that this unit would never be a pathway to increasing student numbers in a chemistry degree. Therefore he employed a chemistry teacher, Dr Simpson, to develop the curriculum so that it only included the parts that mattered and removed all the descriptive chemistry. The qualitative evidence from the focus group interviews and quantitative evidence from the surveys revealed that this is still important to students. The majority of the student cohort views the completion of this unit as an important stepping-stone for their chosen career path. Students in 2013 and 2014 believe that a fundamental understanding of chemistry is required to understand the more applied disciplines of their chosen course of study.

This study, therefore, asks whether an introductory chemistry unit at tertiary level should follow a secondary school curriculum. The chemistry curriculum in secondary school should be aimed at students with an interest in the topic and who potentially wish to continue further studies in a STEM discipline. However, the results in this study suggest that at tertiary level, in an introductory chemistry unit, the majority of students do not wish to continue studying chemistry. Therefore, the curriculum design of this type of unit should reflect the needs of the cohort for their future, not what they may have missed in their past, which is why some introductory science units at a tertiary level are unpopular and have a high failure rate. Although this study is only a snapshot of students undertaking an introductory chemistry unit in an Australian setting it is speculated that the findings will find relevance and context to similar introductory courses offered worldwide in all STEM disciplines.

\section{Supplementary Material}

The complete pre- and post-surveys used as well as the interview protocols are available on the Journal's website.

\section{Conflict of Interest}

The authors declare no conflicts of interest.

\section{Acknowledgements}

The authors thank all the staff and students from the Introductory Chemistry unit during years 2013 and 2014 for agreeing to participate in this study. The authors also make a special thanks to both Emeritus Professor Graham Chandler and Dr Peter Simpson OAM for their time and recollections of the 
Publisher: CSIRO; Journal: CH:Australian Journal of Chemistry

Article Type: research-article; Volume: ; Issue: ; Article ID: CH17359

DOI: 10.1071/CH17359; TOC Head:

beginnings of the Introductory Chemistry unit at The University of Western Australia. The Human Research Ethics Office at the University of Western Australia authorized collection of data in this study under project number RA/4/1/5939. The authors thank Karina Price for useful discussions around the design of the questionnaires. Tristan Clemons is a NHMRC Peter Doherty - Australian Biomedical Fellow and we thank the NHMRC for their support.

\section{References}

$<\mathrm{jrn}>\quad[1] \quad$ J. Kennedy, T. Lyons, F. Quinn, Teach. Sci. 2014, 60, 34.</jrn>

$<$ bok $>$ [2] M. Hughes, S. Prasad, S. White, L. Kusa, W. Howard, J. Baker, et al., Health of Australian Science 2012 (Office of the Chief Scientist: Canberra). $<$ /bok $>$

$<$ bok $>$ [3] D. Goodrum, A. Druhan, J. Abbs, The Status and Quality of Year 11 and 12 Science in Australian Schools 2012 (Australian Academy of Science: Canberra). </bok>

$<$ jrn> [4] H. J. Boon, Aust. Educ. Res. 2012, 39, 17. doi:10.1007/s13384-011-0045-5</jrn>

$<$ bok $>\quad$ 5] C. Schreiner, S. Sjoberg, ROSE: The Relevance of Science Education: Sowing the Seeds of ROSE 2004 (Oslo Department of Teacher Education and School Development, University of Oslo: Oslo). $<$ bok $>$

$<$ jrn $>\quad[6] \quad$ G. Venville, Teach. Sci. 2008, 54, 41.</jrn>

$<$ bok $>$ [7] I. Dobson, Unhealthy Science? University Natural and Physical Sciences 2002 to 2009/10, Report No. XXX 2016 (Office of the Chief Scientist: Canberra).</bok>

$<$ jrn> [8] J. Osborne, S. Simon, S. Collins, Int. J. Sci. Educ. 2003, 25, 1049.

doi:10.1080/0950069032000032199</jrn>
$<\mathrm{jrn}>\quad[9]$
J. M. Ramsden, Int. J. Sci. Educ. 1998, 20, 125. doi:10.1080/0950069980200201</jrn>
$<\mathrm{jrn}>\quad[10]$
P. Gardner, Stud. Sci. Educ. 1975, 2, 1. doi:10.1080/03057267508559818</jrn>
$<\mathrm{jrn}>\quad[11]$
R. Schibeci, Stud. Sci. Educ. 1984, 11, 26. doi:10.1080/03057268408559913</jrn>
$<$ bok $>$ [12]
R. James, K. Krause, C. Jennings, The First Year Experience in Australian
Universities: Findings from 1994 to 20092010 (Centre for the Study of Higher Education, The University of Melbourne and Griffith Institute for Higher Education, Griffith University: Melbourne). $</$ bok $>$

$<$ bok $>\quad[13] \quad$ N. Mbajiorgu, N. Reid, Factors Influencing Curriculum Development in Chemistry

2006 (Higher Education Academy Physical Sciences Centre: Hull). $</$ bok $>$

$<$ jrn> [14] A. Zusho, P. R. Pintrich, B. Coppola, Int. J. Sci. Educ. 2003, 25, 1081.

doi:10.1080/0950069032000052207</jrn>

$<$ jrn $>\quad$ [15] A. Berg, Chem. Educ. Res. Pract. 2005, 6, 1. doi:10.1039/B4RP90001D</jrn> 
Publisher: CSIRO; Journal: CH:Australian Journal of Chemistry

Article Type: research-article; Volume: ; Issue: ; Article ID: CH17359 DOI: $10.1071 / \mathrm{CH} 17359$; TOC Head:

$<$ conf $>$ [16] P. Handwerk, C. Carson, K. Blackwell, Online vs. Paper-and-Pencil Surveying of

Students: A Case Study. 40th Annual Forum of the Association for Institutional Research, 21-24 May 2000, Cincinnati, OH. $<$ conf $>$

$<$ bok $>$ [17] C. Matz, Administration of Web versus Paper Surveys: Mode Effects and Response

Rates 1999 (University of North Carolina: Chapel Hill, NC). $<$ bok $>$

$<$ conf $>$ [18] M. Tomsic, D. Hendel, R. Matross, A World Wide Web Response to Student

Satisfaction Surveys: Comparisons Using Paper and Internet Formats. 40th Annual Meeting of the Association for Institutional Research, 21-24 May 2000, Cincinnati, OH.</conf $>$

$<$ conf> [19] D. Underwood, H. Kim, M. Matier (eds), To Mail or to Web: Comparisons of Survey Response Rates and Respondent Characteristics. 40th Annual Meeting of the Association for Institutional Research, 21-24 May 2000, Cincinnati, OH.</conf $>$

$<$ jrn> [20] $\quad$ L. J. Sax, S. K. Gilmartin, A. N. Bryant, Res. Higher Educ. 2003, 44, 409.

doi:10.1023/A:1024232915870</jrn>

$<$ [21] $\quad$ G. Nicoll, J. Francisco, J. Chem. Educ. 2001, 78, 99. doi:10.1021/ed078p99</jrn>

$<$ jrn $>\quad$ [22] B. Fraser, Sci. Educ. 1978, 62, 509. doi:10.1002/sce.3730620411</jrn>

$<$ jrn $>\quad$ [23] A. Wong, B. Fraser, Asia Pac. J. Educ. 1997, 17, 41.

doi:10.1080/02188799708547761</jrn>

$<$ jrn> [24] J. A. Fredricks, P. C. Blumenfeld, A. H. Paris, Rev. Educ. Res. 2004, 74, 59.

doi:10.3102/00346543074001059</jrn>

$<$ jrn> [25] N. Ultay, M. Calik, J. Sci. Educ. Technol. 2012, 21, 686. doi:10.1007/s10956-011$\underline{9357-5}</ \mathrm{jrn}>$

$<$ bok $>\quad$ [26] T. Lyons, F. Quinn, Choosing Science: Understanding the Declines in Senior High School Science Enrolments 2010 (University of New England: Sydney).</bok>

$<$ bok $>$ [27] R. Bolstad, R. Hipkins, Seeing Yourself in Science: The Importance of the Middle

School Years 2008 (New Zealand Council for Educational Research: Wellington).</bok>

$<$ jrn> [28] J. Bennett, F. Lubben, Int. J. Sci. Educ. 2006, 28, 999.

doi:10.1080/09500690600702496</jrn>

$<$ jrn> [29] I. Parchmann, C. Grasel, A. Baer, P. Nentwig, R. Demuth, B. Ralle, Int. J. Sci. Educ.

2006, 28, 1041. doi:10.1080/09500690600702512</jrn>

$<$ jrn $>\quad$ [30] J. M. Ramsden, Int. J. Sci. Educ. 1997, 19, 697. doi:10.1080/0950069970190606</jrn>

$<$ jrn $>\quad[31] \quad$ Y. Hijazi, M. Tatar, I. Gati, Prof. Sch. Couns. 2004, 8, 64.</jrn>

$<$ jrn> [32] K. M. Galotti, E. Ciner, H. E. Altenbaurner, H. J. Geerts, A. Rupp, J. Woulfe, Pers.

Individ. Dif. 2006, 41, 629. doi:10.1016/j.paid.2006.03.003</jrn>

$<$ jrn $>\quad$ [33] R. M. Mcdaniels, J. K. Carter, C. J. Heinzen, K. I. Candrl, A. M. Wieberg, J. Career

Dev. 1994, 21, 135.</jrn $>$ 
Publisher: CSIRO; Journal: CH:Australian Journal of Chemistry

Article Type: research-article; Volume: ; Issue: ; Article ID: CH17359

DOI: $10.1071 / \mathrm{CH} 17359$; TOC Head:

Fig. 1. Analysis of study cohort 1 and the majors chosen by these students $(n=257)$. Green bars represent where the introductory chemistry unit (or equivalent chemistry) is a prerequisite, yellow where it is highly desired, and red represents a major with no pre-chemistry requirements at all. 'Other' includes 13 majors, each containing only one student enrolled from the cohort, none of which have any prechemistry restrictions.

Fig. 2. Student responses to the role of chemistry in their chosen career path.

Fig. 3. Percentage of students from cohort 1 (2013) and cohort 2 (2014) post survey responses to the following statement: 'As of today, if you had no restrictions on future unit choices, would you choose to enrol in another chemistry unit.'

Fig. 4. Students were questioned with regards to their feelings towards the unit both before and after the completion of the unit for both cohort 1 (2013) and cohort 2 (2014). Data displayed as a total percentage change of all student responses.

Table 1. Student enjoyment of chemistry before and at the completion of the unit Student level of agreement to the following survey statements: ('pre') I enjoyed chemistry at school/('post') I have enjoyed the introductory chemistry unit

\begin{tabular}{|c|c|c|c|c|c|c|}
\hline Agreement indicated & $\begin{array}{c}\text { Cohort } 1 \\
\text { ('pre') }\end{array}$ & $\begin{array}{c}\text { Cohort } 1 \\
\text { ('post') }\end{array}$ & $\%$ Change & $\begin{array}{c}\text { Cohort } 2 \\
\text { ('pre') }\end{array}$ & $\begin{array}{l}\text { Cohort } 2 \\
\text { ('post') }\end{array}$ & $\%$ Change \\
\hline Strongly agree & 7 & 8 & +1 & 9 & 13 & +4 \\
\hline Agree & 28 & 50 & +22 & 32 & 45 & +13 \\
\hline Agree subtotal & 35 & 58 & +23 & 41 & 58 & +17 \\
\hline Neutral/NA & 41 & 28 & -13 & 40 & 31 & -9 \\
\hline Disagree & 19 & 12 & -7 & 13 & 10 & -3 \\
\hline Strongly disagree & 5 & 2 & -3 & 6 & 1 & -5 \\
\hline Disagree subtotal & 24 & 14 & -10 & 19 & 11 & -8 \\
\hline
\end{tabular}

Table 2. Students' perceptions of the applicability of chemistry and the chemistry taught in the unit to 'real life' problems

Student level of agreement with the following survey statements: ('pre') I enjoyed how applicable chemistry is to 'real life' problems/('post') CHEM 1003 has demonstrated to me how applicable chemistry is to 'real life' problems

\begin{tabular}{ccccccc}
\hline Agreement indicated & $\begin{array}{c}\text { Cohort 1 } \\
\text { ('pre') }\end{array}$ & $\begin{array}{l}\text { Cohort 1 } \\
\text { ('post') }\end{array}$ & $\begin{array}{l}\% \\
\text { Change }\end{array}$ & $\begin{array}{l}\text { Cohort 2 } \\
\text { ('pre') }\end{array}$ & $\begin{array}{l}\text { Cohort 2 } \\
\text { ('post') }\end{array}$ & $\begin{array}{l}\% \\
\text { Change }\end{array}$ \\
\hline Strongly agree & 4 & 9 & +5 & 8 & 16 & +8 \\
Agree & 34 & 47 & +13 & 28 & 39 & +11 \\
Agree subtotal & 38 & 56 & +18 & 36 & 55 & +19 \\
Neutral/NA & 42 & 33 & -9 & 47 & 29 & -18 \\
Disagree & 15 & 9 & -6 & 14 & 15 & +1 \\
Strongly disagree & 5 & 2 & -3 & 3 & 1 & -2 \\
Disagree subtotal & 20 & 11 & -9 & 17 & 16 & -1 \\
\hline
\end{tabular}

Table 3. How applicable students felt the unit would be to their future career/study

Student level of applicability indicated for the following survey statements: ('pre') I feel what I will learn in the unit will benefit my career/future study/('post') I feel what I am learning in the unit will benefit my career/future study 
Publisher: CSIRO; Journal: CH:Australian Journal of Chemistry

Article Type: research-article; Volume: ; Issue: ; Article ID: CH17359 DOI: 10.1071/CH17359; TOC Head:

\begin{tabular}{ccccccc}
\hline Applicability indicated & $\begin{array}{l}\text { Cohort 1 } \\
\text { ('pre') }\end{array}$ & $\begin{array}{l}\text { Cohort 1 } \\
\text { ('post') }\end{array}$ & $\begin{array}{c}\% \\
\text { Change }\end{array}$ & $\begin{array}{l}\text { Cohort 2 } \\
\text { ('pre') }\end{array}$ & $\begin{array}{l}\text { Cohort 2 } \\
\text { ('post') }\end{array}$ & $\begin{array}{l}\% \\
\text { Change }\end{array}$ \\
\hline Very applicable & 41 & 18 & -23 & 34 & 17 & -17 \\
Applicable & 36 & 41 & +5 & 34 & 41 & +7 \\
Moderately applicable & 14 & 24 & +10 & 18 & 27 & +9 \\
Only just applicable & 4 & 12 & +8 & 8 & 9 & +1 \\
Not applicable & 5 & 5 & 0 & 6 & 6 & 0 \\
\hline
\end{tabular}

Table 4. Student assessment of the challenge to master difficult chemistry concepts before and at the completion of the unit

Student level of agreement to the following survey statements: ('pre') I enjoyed the challenge of learning difficult chemistry concepts' at school/('post') I have enjoyed the challenge of learning difficult chemistry concepts in the unit

\begin{tabular}{ccccccc}
\hline Agreement indicated & $\begin{array}{l}\text { Cohort 1 } \\
\text { ('pre') }\end{array}$ & $\begin{array}{l}\text { Cohort 1 } \\
\text { ('post') }\end{array}$ & $\begin{array}{l}\text { \% } \\
\text { Change }\end{array}$ & $\begin{array}{l}\text { Cohort 2 } \\
\text { ('pre') }\end{array}$ & $\begin{array}{l}\text { Cohort 2 } \\
\text { ('post') }\end{array}$ & $\begin{array}{l}\% \\
\text { Change }\end{array}$ \\
\hline Strongly agree & 8 & 8 & 0 & 10 & 13 & +3 \\
Agree & 26 & 39 & +13 & 26 & 32 & +6 \\
Agree subtotal & 34 & 47 & +13 & 36 & 45 & \\
& & & & & & \\
Neutral/NA & 43 & 33 & -10 & 41 & 15 & -7 \\
Disagree & 17 & 16 & -1 & 16 & 15 & -1 \\
Strongly disagree & 6 & 4 & -2 & 7 & 6 & -1 \\
Disagree subtotal & 23 & 20 & -3 & 23 & 21 & -2 \\
\hline
\end{tabular}

